\title{
Primary percutaneous coronary intervention ameliorates complete atrioventricular block complicating acute inferior myocardial infarction
}

This article was published in the following Dove Press journal:

Clinical Interventions in Aging

24 November 2014

Number of times this article has been viewed

\section{Su Nam Lee \\ You-Mi Hwang \\ Gee-Hee Kim \\ Ji-Hoon Kim \\ Ki-Dong Yoo \\ Chul-Min Kim \\ Keon-Woong Moon}

Department of Internal Medicine, St Vincent's Hospital, The Catholic University of Korea, Suwon, South Korea
Correspondence: Keon-Woong Moon Department of Internal Medicine, St Vincent's Hospital, \# 93-6, Ji-dong, Paldal-ku, Suwon, Gyunggi-do, 442-723, South Korea

$\mathrm{Tel}+82312497139$

Fax +82 31 2477139

Email cardiomoon@gmail.com
Objective: Complete atrioventricular block (CAVB) in acute inferior ST-segment elevation myocardial infarction (STEMI) is associated with poor clinical outcomes after noninvasive treatment. This study was designed to determine the effect of primary percutaneous coronary intervention (PCI) in patients with CAVB complicating acute inferior STEMI, at a single center.

Methods: We enrolled 138 consecutive patients diagnosed with STEMI involving the inferior wall; of these, 27 patients had CAVB. All patients received primary PCI. The clinical characteristics, procedural data, and clinical outcomes were compared in patients with versus without CAVB.

Results: Baseline clinical characteristics were similar between patients with and without CAVB. Patients with CAVB were more likely to present with cardiogenic shock, and CAVB was caused primarily by right coronary artery occlusion. Door-to-balloon time was similar between those two groups. After primary PCI, CAVB was reversed in all patients. The peak creatinine phosphokinase level, left ventricular ejection fraction and in-hospital mortality rate were similar between the two groups. After a median follow up of 318 days, major adverse cardiac events did not differ between the groups $(8.1 \%$ in patients without CAVB; $11.1 \%$ in patients with $\mathrm{CAVB})(P=0.702)$.

Conclusion: We conclude that primary PCI can ameliorate CAVB-complicated acute inferior STEMI, with an acceptable rate of major adverse cardiac events, and suggest that primary PCI should be the preferred reperfusion therapy in patients with CAVB complicating acute inferior myocardial infarction.

Keywords: major adverse cardiac events, PCI-capable hospital

\section{Introduction}

Complete atrioventricular (AV) block (CAVB) is a common complication of acute myocardial infarction (AMI). High-degree AV block (AVB) is seen about 5\%-7\% of all patients presenting with AMI. ${ }^{1}$ In patients with inferior ST-segment elevation myocardial infarction (STEMI), CAVB has been reported to be as high as $28 \% .^{2-4}$ The exact mechanism underlying AVB remains unclear, although the two most common explanations are interrupted blood flow to the AV node and increased vagal tone resulting from the Bezold-Jarish reaction. ${ }^{5,6}$ In the thrombolytic era, CAVB in inferior AMI has been associated with older age, larger infarct size, and higher in-hospital mortality. ${ }^{3,7,8}$ The in-hospital mortality rate has improved with reperfusion therapy, generally by thrombolysis. ${ }^{3,8,9}$ However it is unknown whether primary percutaneous coronary intervention (PCI) can improve the outcome in patients with CAVB complicating acute inferior STEMI, which was the focus of this study. 


\section{Methods}

\section{Patients}

We enrolled 138 consecutive patients who were diagnosed with STEMI involving the inferior wall, from January 2009 to December 2011. Inferior wall STEMI was defined as typical chest pain or dyspnea lasting longer than 30 minutes, ST-segment elevation $\geq 1.0 \mathrm{~mm}$ in more than two of three inferior leads (II, III, and aVF), and elevated serum creatinine phosphokinase (CPK) or troponin-T levels more than twice the upper limits of normal. There were 27 patients in this group with CAVB. A temporary pacemaker was implanted if there was hemodynamic instability and bradycardia with a heart rate $\leq 40$ beats per minute refractory to intravenous atropine administration. All patients received primary PCI. The clinical characteristics, laboratory data, angiographic findings, PCI procedural data, and in-hospital and long-term clinical outcomes were compared in patients with versus without CAVB. Echocardiographic measurement of left ventricular ejection fraction was performed 1 or 2 days after PCI. This study protocol was approved by the Institutional Review Board (IRB) of St Vincent's Hospital, Suwon, South Korea (IRB number VC11RISI0207).

\section{Statistical analysis}

Analyses were performed using R 2.14.1 statistical software (R Foundation for Statistical Computing, Vienna, Austria). Categorical variables were described using frequencies, while continuous variables were reported as median and interquartile ranges. Fisher's exact test or Pearson's $\chi^{2}$ test with Yates' continuity correction were used to compare categorical variables in patients with versus without CAVB. A two-sided $t$-test was used to compare continuous variables.
The survival of patients with and without CAVB was determined using the Kaplan-Meier method and compared using a logrank test.

\section{Results}

The baseline characteristics of 138 patients are summarized in Table 1. There were no differences in sex, age, smoking status, basal metabolic index, lipid profiles, or prevalence of diabetes mellitus or hypertension between the two groups. However, there were several significant differences in procedural and angiographic data, and clinical outcomes (Table 2). In eleven patients with CAVB (40.7\%) who presented with cardiogenic shock, a temporary pacemaker was implanted, while only four patients (3.6\%) without CAVB underwent temporary pacemaker implantation $(P<0.001)$. Notably, almost all CAVB cases were caused by a right coronary artery infarct (96.3\%) $(P=0.046)$. Door-to-balloon time was similar between the two groups. After primary PCI, CAVB was reversed in all patients. There were no statistical differences in the use of intraaortic balloon pump support (7.4\% in patients with CAVB vs $3.6 \%$ in patients without CAVB), access route (eg, for transradial approach, $48.1 \%$ vs $67.6 \%$ ), peak cardiac enzymes, radiation time, contrast dose, ejection fraction after primary PCI ( $60.3 \%$ vs $58 \%)$ or in-hospital mortality rates ( $7.4 \%$ vs $5.4 \%)$ between groups. After a median 318 days of follow up, the mortality rates were not different between those two groups $(5.4 \%$ in patients without CAVB, $7.4 \%$ in patients with CAVB) $(P=0.654)$ (Table 3$)$, and overall major adverse cardiac events were not different between the two groups $(8.1 \%$ in patients without CAVB, $11.1 \%$ in patients with CAVB) $(P=0.702)$ (Table 3). Finally, KaplanMeier analysis showed a comparable prognosis based on

Table I Baseline characteristics

\begin{tabular}{|c|c|c|c|}
\hline & No AV block $(\mathrm{N}=$ I I I $)$ & Complete AV block ( $N=27)$ & $P$-value \\
\hline Mean age, years (IQR) & $58.0(51.0-70.5)$ & $64.0(59.5-70.0)$ & 0.193 \\
\hline Male, n (\%) & $85(76.6 \%)$ & 21 (77.8\%) & 0.903 \\
\hline Diabetes mellitus, n (\%) & $4 \mathrm{I}(37.3 \%)$ & $8(29.6 \%)$ & 0.458 \\
\hline Hypertension, n (\%) & $58(53.2 \%)$ & $15(55.6 \%)$ & 0.997 \\
\hline Smoking status (\%) & & & 0.325 \\
\hline Never smoker, $\mathrm{n}$ & $33(30.3 \%)$ & $5(18.5 \%)$ & \\
\hline Ex-smoker, $n$ & $22(20.2 \%)$ & $4(14.8 \%)$ & \\
\hline Current smoker, $\mathrm{n}$ & $54(49.5 \%)$ & $18(66.7 \%)$ & \\
\hline BMI, kg/m² (IQR) & $24.5(22.1-26.3)$ & $22.5(20.7-26.8)$ & 0.318 \\
\hline $\mathrm{BMI}>25 \mathrm{~kg} / \mathrm{m}^{2}, \mathrm{n}(\%)$ & 45 (40.5\%) & $10(37.0 \%)$ & 0.909 \\
\hline Total cholesterol, mg/dL (IQR) & $175(153-207)$ & $17 \mid(\mid 50-212)$ & 0.532 \\
\hline Triglyceride, mg/dL (IQR) & $99(65-143)$ & $80(95-157)$ & 0.811 \\
\hline LDL-cholesterol, mg/dL (IQR) & II $15(90-140)$ & $118(95-152)$ & 0.489 \\
\hline HDL-cholesterol, mg/dL (IQR) & $38(31-44)$ & $39(33-44)$ & 0.785 \\
\hline
\end{tabular}

Abbreviations: $\mathrm{N}$, numbers of subjects; IQR, interquartile range; AV, atrioventricular; BMI, body mass index; CAVB, complete atrioventricular block; HDL, high-density lipoprotein cholesterol; LDL, low-density lipoprotein cholesterol. 
Table 2 Procedural data, angiographic data and clinical outcomes

\begin{tabular}{|c|c|c|c|}
\hline & No AV block $(N=I I I)$ & Complete AV block $(\mathrm{N}=27)$ & $P$-value \\
\hline Temporary pacemaker, n (\%) & $4(3.6 \%)$ & II (40.7\%) & $<0.001$ \\
\hline Cardiogenic shock, n (\%) & $16(14.0 \%)$ & II (40.7\%) & 0.005 \\
\hline IABP, n (\%) & $4(3.6 \%)$ & $2(7.4 \%)$ & 0.334 \\
\hline Transradial access, n (\%) & $75(67.6 \%)$ & $13(48.1 \%)$ & 0.097 \\
\hline Door-to-balloon time, $\min (\mathrm{IQR})$ & $82(65-112)$ & $76(57-106)$ & 0.617 \\
\hline \multicolumn{4}{|l|}{ Infarct-related artery } \\
\hline Right coronary artery, n (\%) & $89(80.2 \%)$ & $26(96.3 \%)$ & 0.046 \\
\hline Left circumflex artery, $\mathrm{n}(\%)$ & $22(19.8 \%)$ & I (3.7\%) & \\
\hline \multicolumn{4}{|l|}{ Culprit lesion } \\
\hline Proximal RCA, n (\%) & 21 (I8.9\%) & 9 (33.3\%) & \\
\hline Mid-RCA, n (\%) & $29(26.1 \%)$ & $12(44.4 \%)$ & \\
\hline Distal RCA, n (\%) & $33(29.7 \%)$ & $5(18.5 \%)$ & \\
\hline rPDA, n (\%) & $2(1.8 \%)$ & $0(0.0 \%)$ & \\
\hline Ist RPL, n (\%) & $4(3.6 \%)$ & $0(0.0 \%)$ & \\
\hline Proximal LCX, n (\%) & $3(2.7 \%)$ & $0(0.0 \%)$ & \\
\hline Distal LCX, n (\%) & $16(14.0 \%)$ & I (3.7\%) & \\
\hline CPK peak, U/L (IQR) & I,665 (385-2,780) & I,893 (I,203-2,949) & 0.309 \\
\hline CK-MB peak, U/L (IQR) & $134(50-2 \mid 4)$ & $146(64-396)$ & 0.114 \\
\hline Fluoroscopy time, $\min (\mathrm{IQR})$ & $11.5(9.0-18.2)$ & $10.2(9.0-18.3)$ & 0.719 \\
\hline Contrast use, $\mathrm{mL}$ (IQR) & $180(140-218)$ & $143(98-205)$ & 0.079 \\
\hline $\mathrm{EF}(\%)$ after $\mathrm{PCl}(\mathrm{IQR})$ & $58.0(51.9-61.1)$ & $60.3(53.0-63.8)$ & 0.408 \\
\hline In-hospital death, $\mathrm{n}(\%)$ & $6(5.4 \%)$ & $2(7.4 \%)$ & 0.654 \\
\hline
\end{tabular}

Abbreviations: $\mathrm{N}$, numbers of subjects; IQR, interquartile range; $\mathrm{AV}$, atrioventricular; IABP, intra-aortic balloon pump; RCA, right coronary artery; LCX, left circumflex artery; PDA, posterior descending artery; RPL, right posterolateral artery; CK-MB, creatinine phosphokinase; CPK, creatinine phosphokinase; EF, ejection fraction; PCI, percutaneous coronary intervention.

major adverse cardiac events, between patients with and without CAVB in acute inferior wall STEMI (Figure 1).

\section{Discussion}

CAVB is a common complication of AMI. In particular, patients with inferior AMI are more prone to developing CAVB compared with patients with anterior AMI. STEMI increases the risk of CAVB compared with patients with non-STEMI. ${ }^{9,10}$

The exact mechanism underlying AVB remains unclear. However, there are two most common mechanisms for cardiogenic shock and bradyarrhythmia in inferior AMI. The first involves cardioinhibitory (Bezold-Jarisch) reflexes arising from vagal efferents in the ischemic left ventricular inferoposterior wall. ${ }^{7}$ The second involves the effects of AV nodal ischemia. ${ }^{2,11-12}$

Table 3 Major adverse cardiac events during follow-up

\begin{tabular}{llll}
\hline & $\begin{array}{l}\text { No AV block } \\
(\mathbf{N}=\mathbf{I} \text { I I) }\end{array}$ & $\begin{array}{l}\text { Complete AV block } \\
(\mathbf{N}=\mathbf{2 7})\end{array}$ & P-value \\
\hline Death, n (\%) & $6(5.4 \%)$ & $2(7.4 \%)$ & 0.654 \\
Reinfarction, $\mathrm{n}(\%)$ & $3(2.7 \%)$ & $\mathrm{I}(3.7 \%)$ & $\mathrm{I}$ \\
TVR, n (\%) & $3(2.7 \%)$ & $0(0.0 \%)$ & $\mathrm{I}$ \\
MACE, n (\%) & $9(8.1 \%)$ & $3(11.1 \%)$ & 0.702 \\
\hline
\end{tabular}

Abbreviations: $\mathrm{N}$, numbers of subjects; $\mathrm{AV}$, atrioventricular; TVR, target vessel re-infarction; MACE, major adverse cardiac event.
In our study, we investigated the prognostic significance of CAVB in 138 patients with inferior STEMI treated with primary PCI. There were 27 patients in this group with CAVB, and all patients received primary PCI. The in-hospital mortality rates and major adverse cardiac events were not different independent of CAVB.

Previous studies during the thrombolytic era determined that patients with inferior AMI complicated by CAVB had a higher Killip class and an increased risk of in-hospital events, such as cardiogenic shock, AV arrhythmias, and short-term (30-day) mortality rate., ${ }^{2,1314} \mathrm{Jim}$ et al previously conducted a single-center trial in Hong Kong to determine the impact of CAVB in acute inferior MI and concluded that the in-hospital mortality was significantly higher in patients with CAVB. However, in this study, the main treatment was thrombolysis (50\%) and medical treatment (44.3\%), not the primary PCI (5.7\%). ${ }^{8}$ Also, Pirzada et al reported high-degree AVB significantly influenced the outcome when associated with right ventricular infarction, leading to high mortality in acute inferior MI. Similarly, in this study, $73 \%$ received thrombolytic therapy among patients with $\mathrm{AVB},{ }^{3}$ while, Gang et al investigated the prognostic significance of highdegree AVB in STEMI patients treated with primary PCI and found that the mortality rate was significantly increased in patients with high-degree AVB. However in the study by 


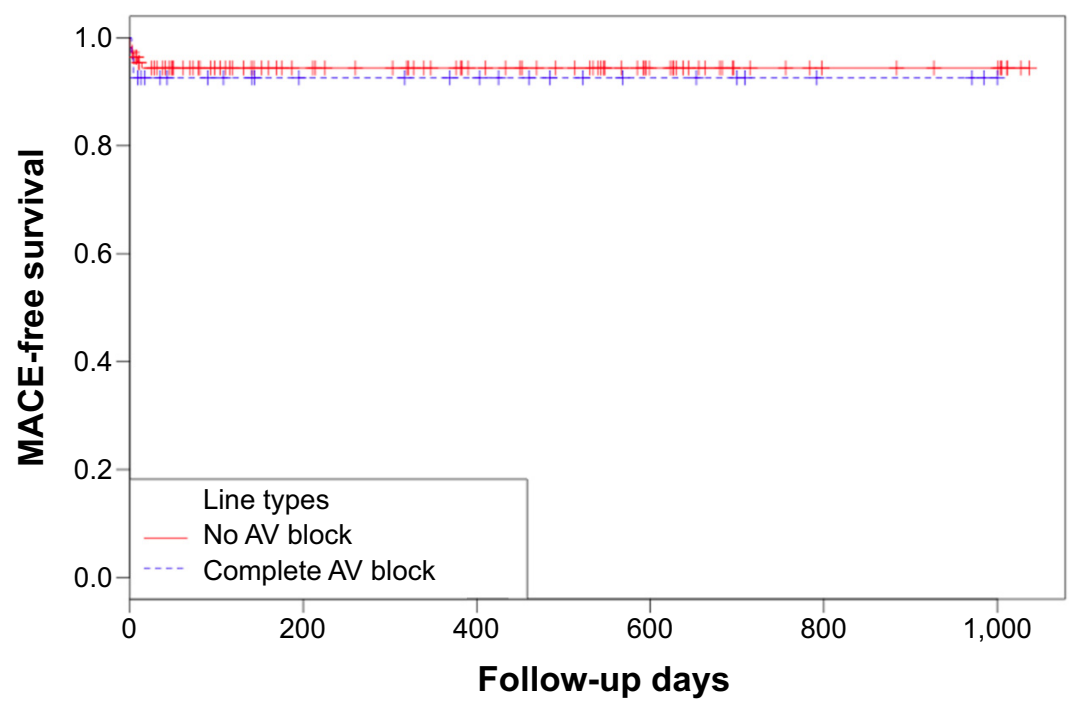

Figure I Kaplan-Meier analysis for survival from major adverse cardiac events.

Notes: Kaplan-Meier analysis showing the MACE-free survival of patients with acute ST-segment elevation myocardial infarction involving the inferior wall who developed CAVB, compared with those who did not have CAVB. Log-rank test: $P=0.642$.

Abbreviations: $\mathrm{AV}$, atrioventricular; $\mathrm{CAVB}$, complete atrioventricular block; MACE, major adverse cardiac event.

Gang et al all patients of STEMI were included regardless of infarct location, and the door-to-balloon time in the two groups was not compared. ${ }^{9}$ In these previous studies, the main treatment was thrombolysis or medical treatment, not the primary PCI, and they did not compare the procedural and angiographic data, while in our study, all patients received primary PCI, and procedural and angiographic data were compared in patients with versus without CAVB. Even though successful treatment of inferior AMI presenting with CAVB by reperfusion therapy has been reported frequently in the primary PCI era, ${ }^{8-10,15,16}$ whether primary PCI could improve the outcome in patients with acute inferior STEMI presenting with CAVB has not been determined. In our study, all patients received primary PCI (median door-to-balloon time 80.5 minutes $[61.75,107.8$, range] minutes); as a result, the mortality rates and major adverse cardiac events were not different independent of CAVB.

The overall experience with heart block occurring in association with acute inferior infarction indicates that heart block is responsive to atropine or isoproterenol in the majority of cases, usually does not require placement of a temporary pacemaker, and almost never requires implantation of a permanent pacemaker. ${ }^{17}$ Current guidelines recommend that temporary pacing is indicated for symptomatic bradyarrhythmias unresponsive to medical treatment. ${ }^{18}$ Ho et al reported the reversibility of CAVB in patients with anterior AMI. CAVB resolved after percutaneous transluminal coronary angioplasty in $88 \%$ of patients, and the mean time of resolution was $89 \pm 144$ minutes after revascularization. ${ }^{16}$ However in our study, even though we did not measure the mean time of resolution, CAVB was reversed in all patients after the primary PCI procedure, and no patient required a permanent pacemaker.

In our study, results showed neither increase in the risk of in-hospital events, nor follow up major adverse cardiac events in the CAVB group compared with the non-CAVB group. Furthermore, CAVB was reversed in all patients after primary PCI. This result is contrary to previous reports that CAVB complicating inferior STEMI is associated with poor cardiovascular outcome. Thus, we suggest that primary PCI could ameliorate CAVB complicating acute inferior MI if performed in timely fashion.

Our study had several limitations. First, the present study was conducted with a relatively small number of patients, resulting in insufficient power to generalize. However, this study was designed to determine the effect of primary PCI in patients with CAVB complicating acute inferior STEMI at a relatively large-scale center. Even though the numbers were small, significant results were obtained, which underlies the value of the conclusion. Second, the follow-up period was too short to generalize any long-term outcomes. Third, to estimate the effect of primary PCI, we should have included a control group consisting of patients treated with thrombolysis during the same time period at the same center; however, it was considered unethical to treat patients with STEMI with thrombolysis at a PCI-capable hospital because current guidelines recommend that STEMI patients arrived at a PCI-capable hospital should receive primary PCI. ${ }^{18}$ 
Our study also had several strengths. First, it was conducted using a discrete population of inferior STEMI patients from one center during a 3-year period, with consistent criteria for CAVB. Although primary PCI is usually recommended for all STEMI patients in modern days, there have been no other studies conducted specifically in inferior STEMI to define the prognostic implication of primary PCI on CAVB in such a clinical setting. Moreover, in our study, all patients received primary PCI. After primary PCI, CAVB was reversed in all patients. Based on this result, the most probable mechanism of bradyarrhythmia in inferior AMI was considered to be Bezold-Jarisch reflexes, not AV nodal ischemia. In our hospital, a temporary pacemaker was implanted if there was hemodynamic instability and bradycardia with a heart rate $\leq 40$ beats per minute that was refractory to intravenous atropine administration in the past. Although recently we performed primary PCI without temporary pacing in STEMI patients with $\mathrm{CAVB}$, all patients were stable and CAVB was reversed with primary PCI. This could be elucidated further by prospective studies investigating the effect of revascularization on CAVB reversibility in inferior STEMI.

In conclusion, primary PCI can ameliorate CAVBcomplicated acute inferior STEMI, with an acceptable rate of major adverse cardiac events. Our results suggest that primary PCI should be the preferred reperfusion therapy in patients with CAVB complicating acute inferior MI.

\section{Disclosure}

The authors report no conflicts of interest in this work.

\section{References}

1. Rathore SS, Gersh BJ, Berger PB, et al. Acute myocardial infarction complicated by heart block in the elderly: prevalence and outcomes. Am Heart J. 2001;141(1):47-54.

2. Berger PB, Ryan TJ. Inferior myocardial infarction. High-risk subgroups. Circulation. 1990;81(2):401-411.

3. Pirzada AM, Zaman KS, Mahmood K, Sagheer T, Mahar SA, Jafri MH. High degree Atrioventricular block in patients with acute inferior Myocardial Infarction with and without Right Ventricular involvement. J Coll Physicians Surg Pak. 2009;19(5):269-274.

4. Chiu CA, Youssef AA, Wu CJ, et al. Impact of PercuSurge GuardWire device on prevention and reduction of recovery time from complete heart block in patients with acute inferior myocardial infarction undergoing primary percutaneous coronary intervention. Int Heart J. 2007;48(1):35-44.
5. Goldstein JA, Lee DT, Pica MC, Dixon SR, O’Neill WW. Patterns of coronary compromise leading to bradyarrhythmias and hypotension in inferior myocardial infarction. Coron Artery Dis. 2005;16(5): 265-274.

6. Mark AL. The Bezold-Jarisch reflex revisited: clinical implications of inhibitory reflexes originating in the heart. $J$ Am Coll Cardiol. 1983;1(1): 90-102.

7. Kosuge M, Kimura K, Ishikawa T, et al. Clinical features of patients with reperfused inferior wall acute myocardial infarction complicated by early complete atrioventricular block. Am J Cardiol. 2001;88(10): 1187-1191.

8. Jim MH, Chan AO, Tse HF, Barold SS, Lau CP. Clinical and angiographic findings of complete atrioventricular block in acute inferior myocardial infarction. Ann Acad Med Singapore. 2010;39(3):185-190.

9. Gang UJ, Hvelplund A, Pedersen S, et al. High-degree atrioventricular block complicating ST-segment elevation myocardial infarction in the era of primary percutaneous coronary intervention. Europace. 2012;14(11): 1639-1645.

10. Hwang IC, Seo WW, Oh IY, Choi EK, Oh S. Reversibility of atrioventricular block according to coronary artery disease: results of a retrospective study. Korean Circ J. 2012;42(12):816-822.

11. Adgey AA, Geddes JS, Mulholland HC, Keegan DA, Pantridge JF. Incidence, significance, and management of early bradyarrhythmia complicating acute myocardial infarction. Lancet. 1968;2(7578): 1097-1101.

12. Webb SW, Adgey AA, Pantridge JF. Autonomic disturbance at onset of acute myocardial infarction. Br Med J. 1972;3(5818):89-92.

13. Rotman M, Wagner GS, Wallace AG. Bradyarrhythmias in acute myocardial infarction. Circulation. 1972;45(3):703-722.

14. Aplin M, Engstrøm T, Vejlstrup NG, Clemmensen P, Torp-Pedersen C, Køber L; TRACE Study Group. Prognostic importance of complete atrioventricular block complicating acute myocardial infarction. Am J Cardiol. 2003;92(7):853-856.

15. Bhalli MA, Khan MQ, Samore NA, Mehreen S. Frequency and clinical outcome in conduction defects in acute myocardial infarction. J Ayub Med Coll Abbottabad. 2009;21(3):32-37.

16. Giglioli C, Margheri M, Valente S, et al. Timing, setting and incidence of cardiovascular complications in patients with acute myocardial infarction submitted to primary percutaneous coronary intervention. Can J Cardiol. 2006;22(12):1047-1052.

17. Ho KW, Koh TH, Wong P, et al. Complete atrioventricular block complicating acute anterior myocardial infarction can be reversed with acute coronary angioplasty. Ann Acad Med Singapore. 2010;39(3): 254-257.

18. Sclarovsky S, Strasberg B, Hirshberg A, Arditi A, Lewin RF, Agmon J. Advanced early and late atrioventricular block in acute inferior wall myocardial infarction. Am Heart J. 1984;108:19-24.

19. O’Gara PT, Kushner FG, Ascheim DD, et al; American College of Emergency Physicians; Society for Cardiovascular Angiography and Interventions. $2013 \mathrm{ACCF} / \mathrm{AHA}$ guideline for the management of ST-elevation myocardial infarction: a report of the American College of Cardiology Foundation/American Heart Association Task Force on Practice Guidelines. J Am Coll Cardiol. 2013;61(4):e78-e140.
Clinical Interventions in Aging

\section{Publish your work in this journal}

Clinical Interventions in Aging is an international, peer-reviewed journal focusing on evidence-based reports on the value or lack thereof of treatments intended to prevent or delay the onset of maladaptive correlates of aging in human beings. This journal is indexed on PubMed Central, MedLine,

\section{Dovepress}

CAS, Scopus and the Elsevier Bibliographic databases. The manuscript management system is completely online and includes a very quick and fair peer-review system, which is all easy to use. Visit http://www.dovepress. com/testimonials.php to read real quotes from published authors. 